curiosity that impels one to learn everything that is known about a given subject, and then to go further and broaden and extend that knowledge by personal investigation and research, in spite of all difficulties and discouragements-and these are always many.

The spirit of science is inborn, though it may appear in anybody, anywhere, in any class, or group, or race. In order to develop the scientific spirit to the maximum, as it must be developed if we are to hold our place in the world of the future, we must watch for it at its inception, and whenever and wherever it is found encourage it.

\section{STATISTICAL CONTROL OF PRODUCTION*}

\author{
By DR. C. G. DARWIN, F.R.S. \\ National Physical Laboratory
}

$\mathrm{F}$

$R$ a number of years I had been interested in the general question of tolerances, first from the point of view of pure science and later in its more practical aspects. My interest in this subject was very much focused when I came to the National Physical Laboratory, where I found that work was being done on the actual verification of manufacturing and inspection gauges; this work, of course, deals with the subject in an enhanced degreesquared, so to speak, because there is not only to be considered the tolerance of the work, but also the tolerances on both the go and the not-go gauges which are to check the work.

From internal evidence of the gauge drawings, it looked as if some of the tolerances were assigned much closer than should be necessary, and I started to try to find out how they had been fixed. To accomplish this, on every occasion when I met an engineer I asked him how he decided the tolerances in his branch of the subject; I fear I bored a great many people at this time. I got a variety of answers which sometimes explained things a bit, but often not at all, and though I discussed it with quite a number of men, many of them occupying prominent places in different branches of the profession, I came away with the impression that scarcely any of them were really interested in the subject of tolerances. To exaggerate the picture which $I$ got as the result of my inquiry, I concluded that in designing a new machine the chief engineer drew it free-hand with dimensions to the nearest inch, and sent it to the draughtsman to work out the detail to the nearest thousandth, who then gave it to his junior assistant to mark in the tolerances. Instructions were certainly always given that tolerances should be as easy as possible, but only lip service was done to them, and the junior assistant, anxious not to get himself into trouble, would, as a general rule, think of the smallest number he knew and then halve it. This is a caricature, of course, and has some of the absurdity of one, but also perhaps just a little of the resemblance. Seriously, it seemed to me that there was a defect in the habit of thought of many in the engineering profession, and that some sort of campaign was needed to inculcate in people's minds the idea that every number has a fringe, that it is not to be regarded as exact but as so much plus or minus a bit, and that

* From a paper before a joint meeting of the Institutions of Civil, Mechanical and Electrical Engineers held on April 15. the size of this bit is one of its really important qualities.

Without any very clear idea of where to catch hold of the subject, I had full intention of trying to do something about it at the time I went to the United States a year ago. There I came across the method of 'statistical control' of mass production, and it was obvious at once that this is the right approach. Similar work has been done in Great Britain too, in particular by the staff of the General Electric Company and by members of the Royal Statistical Society, and it was perhaps ill-luck that I never came across it before crossing the Atlantic ; but that I did not shows that it was not very widely known. I would add that it is not by any means very widely used yet in the United States, though the use is spreading. In both countries it has been principally used in industries associated with electricity, such as the telephone industry, but I want to einphasize that it should be of even greater importance in the mechanical industries, and that it is specially applicable to a business like the manufacture of munitions in all their aspects.

One of the important points in the new method is that it gives reasoned instead of guessed values to the tolerances. I will take as an example the making of time fuses for anti-aircraft, and I am giving away no military secrets in doing so, since I shall invent the data and miss out a lot of other considerations that would really enter. Suppose that the lethal area of a bursting shell is such that, if it explodes within a tenth of a second of the set time, it will make a kill. The gunner therefore demands of the manufacturer that he make a fuse with accuracy a tenth of a second. The manufacturer works out his method, but finds that whereas it is easy to get one to a fifth of a second, he will have a lot of trouble to get to a tenth, and, indeed, he estimates that for the same effort of work and cost he could not hope to get more than a quarter as many fuses if they must have the accuracy of a tenth. Now half his shells will burst within the range I asked for and so, in fact, I shall be wise if I accept his inferior fuse, since I shall thereby get four times as many shells of which half will do what I want, and I shall therefore double the rate of killing. I need not say that $I$ have oversimplified the business; on one side I have missed out the cost of the other parts of the shells, and on the other, I have forgotten that the gunner has uncertainties of range to consider, so that his demand for a tenth of a second is more exact than he can justify for practical use.

My example is intended to show that it is good business for the user and the maker of any article to get together before deciding the tolerances of manufacture. The user may be inclined at first to feel that in doing this he is surrendering some of his freedom of choice, but if you consider it closer you will see that this is not so. He has not got any real freedom of choice, since he must surely try to design the article so as to be as easy to make as possible, but he has foregone the quantitative information of what will in fact prove to be easy, and above all of what thing, easy to make, will be good enough for the job. I may summarize this aspect of the matter by saying that the user has tended to demand that everything should be made for him as well as possible, but he ought to want everything to be made for him as badly as possible, or perhaps not quite that, but as badly as permissible. It is in this aspect that statistical control specially gives the right information. 
There are a good many varieties of procedure calleà for in the circumstances of applying statistical control. First, there are the two classes according to whether it is a quantity or a quality that is concerned. It may be a measure, say, of a length or perhaps an electrical resistance, which has to fall within certain prescribed limits; for this we can measure each specimen and record it for analysis. In other cases the test is qualitative, in that the specimen either passes a test or fails to pass-for example, a vessel is watertight or not; and even the measure of a length may fall in this class if it is tested with a gauge, so that the answer is given in the form that it passes or fails to paiss the gauge. Then there is another distinction that divides either type of work into two classes. Some tests, such as a measure of length, can be applied to every article made. but other tests are destructive of the specimen; for example, the test of the force of an explosive or of the tensile strength of a bar. In this last case the test must of necessity only be done on a sample, and it is obviously important to take the sample as small as permissible. Moreover, even in the case where every specimen could be tested, there will be great economy in only doing it for a sample; so that, in fact, we may reckon that sampling is one of the main features of the process, and to determine the advisable fraction of the whole number that must be sampled is an important part of the duty of the statistician. Then again the practical problem of statistical control itself falls into two parts, for there is first the business of starting a new process and getting it into statistical control, and then the business of carrying it on later, after the control has been established. All these matters are described in the British Standards Institution publications B.S. 1008 and 600 (revised), but I shall content myself with giving a very crude sketch of a single example.

The example I shall take is based on one I learnt about in the United States, and I am intentionally leaving the details incorrect and falsifying some of the facts. I learnt about it from Colonel Simon, who

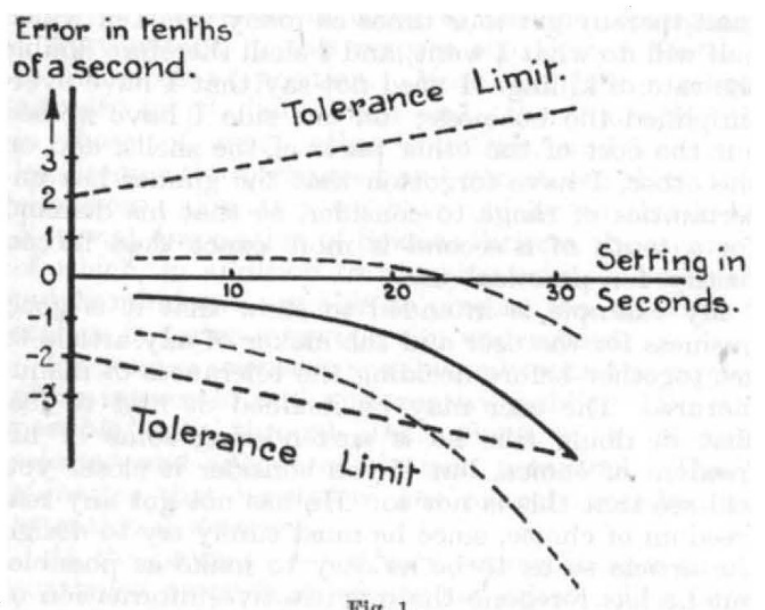

has shown great brilliance in developing the methods for munitions in the U.S. arsenals. The subject was a particular type of time-fuse, and the gunners had assigned certain limits of tolerance which are described in the diagram (Fig. 1). The manufacturers all had great trouble in satisfying the demand for the longer times, so that the tolerances were exceeded both above and below, and Simon was called in to set the matter right. This he did, but to simplify the story we will imagine he had been in at the start, and describe how the process might have gone. It is first necessary to be sure that the process is "in control', in the technical sense of the term. We take a considerable batch of the fuses, keeping them sorted according to time and place of manufacture. Group these sets (or probably samples of them) in batches
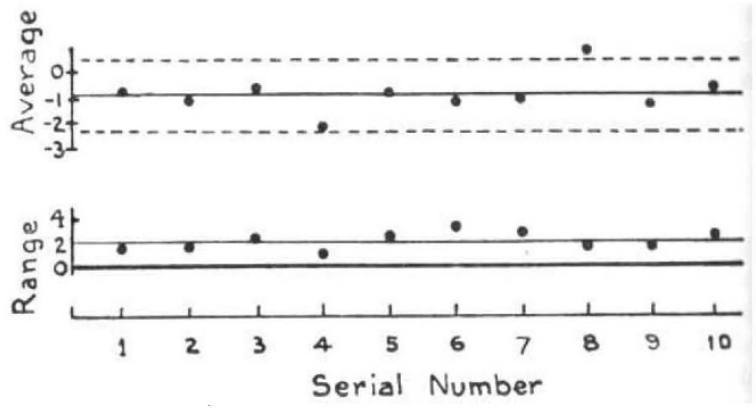

Fig. 2.

of five and set the fuses at 20 sec. Time each fuse, and work out the mean of each batch and its 'range', that is to say, the difference between the shortest and longest among the five. These are marked on two charts in a way described on the British Standards Institution publication (Fig. 2). From the 'range' chart it is possible with the help of tables that have been constructed by statisticians to draw on the other a pair of limits within which the dots should fall. Perhaps they will not do so; say the dots for fuses made by one particular tool fall outside. This gives sure knowledge that something is wrong with the processthe statistician cannot say what, though I was told of cases where he could go so far as to say either that there was only one thing wrong or else certainly several things wrong. It is for the engineer to reexamine his process and find the fault. Next, of course, similar work must be done at the other fuse settings. Suppose this has been done, and that the whole system is in control, and that the accuracy is good enough for the user. After this, much less sampling is needed, but every so often a group should be taken and tested in the same way; I will not go into detail, but this sampling will nearly always give warning of pending trouble, before the trouble is so bad that the fuses would actually fail in passing their test.

Returning to the actual history of these fuses, Simon plotted average time and 'range' for batches of five fuses at various timings of the fuse, and got the curves I show (Fig. 1) for the average timing and for the dotted lines on either side between which all values will fall. This was for the fuses of one manufacturer, and there were similar curves, some up and some down, for the others. It will be seen that the fuses mostly failed to fulfil specification at 20 sec. and above, and yet their tolerance was much finer than that which had been specified. This could be overcome in a variety of ways; for example, by regraduating the markings of the time on the fuse. The result was thus that an article which systematically failed to pass its test, was, with a quite trivial change, found to be actually better than had been asked for. I may add that as a consequence of his work Simon found that the old tests had destroyed something like twice as many of the fuses as is now necessary. 
I will conclude with a few general remarks. When I first came across the method I knew it was of the greatest importance, but I doubted if the middle of a war was the time to start it. I asked this very question of two of the experts in the Bell Laboratory, and both contradicted this first thought of mine and said that it could be applied piecemeal to one process after another without delay in production. Then, as showing how quickly people could adapt them. selves to it, I may recount an incident I experienced. Immediately after visiting Colonel Simon, I happened to be at Frankford Arsenal, which in peace-time was the principal factory making ammunition for the U.S. Army. As such, I expected it would be rather conservative and that it might be suspicious of newfangled methods, and I therefore asked one of the chief colonels there what he thought of these methods, which, I may emphasize, are quite new in their application to military stores. His reply was that it seemed the only sensible way of doing the business.

Another point well worth consideration is that many works have already existing a mass of data of the kind used by the statistician, but they do not submit them to the same analysis. In such cases the change of procedure would be only slight, and a greatly improved control would be obtained by applying the statistical method.

Thirdly, the method gives information about the size of sample that should be tested. In some cases it may be inadequate, whereas in others it will be found that testing a much smaller sample would give sufficiently reliable information on the quality of the whole.

We cannot, of course, expect that the method is a panacea for all troubles, and $I$ expect in some cases it will be tried and prove unsuitable; but I will venture the forecast that the opposite will much more often be the case, and that many processes to which at first sight it seems inapplicable will later be found to benefit greatly by the introduction of statistical control.

\section{OBITUARIES}

\section{Mr. W. P. Pycraft}

William Plane Pycraft, who died on May 1, was a well-known ornithologist and comparative anatomist. He was born at Great Yarmouth in 1868 and while a schoolboy was attracted to natural history by the wild life of the Norfolk Broads. $\mathrm{He}$ became a keen observer of all living things, but devoted himself specially to birds. After leaving school, he desired to follow natural history as a profession, and started as a private pupil with the curator of the Leicester Museum, where he learned the art of preserving and preparing animals for study and exhibition. In 1892 he was introduced to Prof. (afterwards Sir) Ray Lankester, who invited him to be his assistant in making preparations for the Oxford University Museum. While thus occupied he attended Lankester's lectures and demonstrations, and thus extended his outlook by acquiring a good knowledge of the structures and relationships of animals. When Lankester was appointed director of the British Museum (Natural History) in 1898, Pycraft accompanied him to London and became his temporary assistant there. Soon afterwards he joined the permanent staff of the Zoological Department of the Museum, where he remained as an assistant until his retirement in 1933. He spent his later life at Longcross near Chertsey, Surrey, in surroundings where he could continue the field observations which he had begun in early youth.

The original researches carried out by Mr. Pycraft were concerned chiefly with the anatomy of birds. His first paper, published in the Ibis in 1895, described and discussed the arrangement of the feathers in the Tinamous, and in 1898 he contributed a memoir on the feathering of the owls to the Trans. actions of the Linnean Society. Between 1898 and 1907 he wrote a valuable series of nine papers on the osteology of birds published in the Proceedings of the Zoological Society, and in 1900 he discussed the morphology and phylogeny of the Palæognathæ and Neognathæ in an extensive memoir in the Transactions of the same Society.

Mr. Pycraft also began to take much interest in the variations of the human skull, and in 1915 he proposed to substitute for the Frankfort baseline another line which passed wholly through the cranium avoiding the upper part of the face. This proved to be not generally acceptable, and he returned to the subject in a paper in Man in 1925. He wrote several accounts of human skulls, the most noteworthy being his description of the Boskop fossil from South Africa in the Journal of the Royal Anthropological Institute of 1913, and a description of the Rhodesian fossil skull in a British Museum volume in 1928. He took part in several discussions on the Piltdown skull, and in 1917 published in Science Progress an account of the lower jaw which pointed out its differences from the jaw of an ape.

Mr. Pycraft was also a prolific writer of popular books and articles on natural history, which brought him a large correspondence and not infrequently led to the discovery of new facts. His first popular books were the small "Stories of Bird Life", "Fish Life" and "Reptile Life", published by Newnes in London between 1900 and 1905. "A History of Birds", a more serious work, appeared in 1910, and his "Birds of Great Britain" followed in 1934. His volumes on the "Infancy of Animals", "The Courtship of Animals" (1913) and "Camouflage in Nature" (1925) are especially readable and contain original observations. His weekly article in the Illustrated London News was a much-appreciated feature of this paper for many years, and attracted wide attention.

In all his writings Mr. Pycraft showed great interest in the possible mode of evolution of the various structures and habits which he described, and an address on "Some New Aspects of Evolution" which he delivered to the Norfolk and Norwich Naturalists' Society in 1935 was reprinted in the annual report of the Smithsonian Institution, Washington, in the following year. His style was sometimes forceful, for when he had formed an opinion he could not readily be persuaded that it might be mistaken; but he had a versatile mind and was always inspiring. He is mourned by a large circle of friends who learned the more to appreciate him the closer they were associated with him.

\section{A. S. WOODWARD.}

WE regret to announce the following deaths :

Prof. Charles Cohen, formerly of the Brussels Pasteur Institute, aged sixty-one.

Dr. R. L. Ditmars, the distinguished herpetologist, formerly curator of mammals and reptiles in New York Zoological Park, on May 12, aged sixty-five. 